\title{
BICYCLE LEVEL OF SERVICE MODEL FOR THE CYCLORUTA, BOGOTA, COLOMBIA
}

Inah Eteng OKON, Eng. Department of Geography \& Environmental Science, University of Calabar, Calabar, Nigeria, inah.okon@unical.edu.ng

Carlos A. MORENO, Eng. Faculty of Architecture, Universidad Piloto de Colombia, Colombia

\section{Abstract}

Segment videos were produced at different peaks to reflect different sampling criteria like land use characteristics, trails, Ciclocarrils and Ciclovia. Each segment was filmed for $20-40$ seconds during bicycle rides at a speed of about $5 \mathrm{~km} / \mathrm{h}$ with a camera strapped, at an angle of 45 degrees, on the head. Curb lane variables such as bicycle pathway widths, curb lane motorised volume $(\mathrm{veh} / \mathrm{h})$ and vehicle speed $(\mathrm{km} / \mathrm{h})$, bicycle volume on segment, and median width were recorded in addition to secondary data. About 1,360 ratings were acquired from study participants and used in the estimation process. Ordered probability models were used to estimate random parameters of cyclists LOS perception to account for unobserved heterogeneity for all respondents. The deviance (1.085) and Pearson Chi-Square (2.309) with 1,635 degree of freedom at 0.05 level of significance shows that our model provides a better fit of the data. The study observed that BLOS was strongly influenced by side path separation, vehicle speed, motorised traffic volume and conflicts with pedestrians. However, many other factors were found to have high probabilities to influence level of service with unit change. They include bicycle lane width, wide outside lane, pavement conditions, trees and benches, daylight, gender and experience of cyclist. The impact of the variety of observed factors affecting bicyclists reveal the nature and character of urban transportation in Bogota which suggests a range of important trade-offs in further planning and management of the Cicloruta bicycle paths.

Keywords: bicyclist; bicycle level of service, ordered probit models, Cicloruta.

\section{INTRODUCTION}

The role of transport in the reduction of global carbon dioxide emissions has reinforced the widely known necessity for the development of nonmotorised transport (Hickman, Saxena, Banister, \& Ashiru, 2012; Hull, 2010; Kenworthy, 2008). Many countries developed a 'low carbon green growth' as a national vision, thus promoting the use of bicycle as a mitigating factor against traffic congestion and carbon emission. For instance the South Korean government's plan that was aimed at expanding bicycle lanes from 9,170 km to $17,600 \mathrm{~km}$ as at 2012 - by the year / starting as of 2012 - (KMOCT, 2001); the 
ROMANIAN JOURNAL

OF TRANSPORT INFRASTRUCTURE

Inah Eteng OKON , Carlos A. MORENO

Bicycle level of service model for the cycloruta, Bogota, Colombia

Netherlands' more than $70 \%$ of intra-urban commuter journeys in Amsterdam and Hague undertaken by bicycles (BBC News Magazine, 2013); and the high 'daily cycling levels, bike sales, safety, cycle tourism and advocacy activity' in many European countries including Denmark, Netherlands, Sweden, Finland, Germany, Belgium, Austria, Hungary, Slovakia, and United Kingdom.

The task of providing accessibility and mobility to all commuters in the city in a sustainable manner remains complex due to the conflicting modal choices of commuters, different income classes and preferences, safety concerns and the lack of supporting infrastructure for some of these modes. The inability to strike a balance between modes that reduce pollution and those that reduce speed or accidents has also been of concern to transport planners. For instance, increasing the average vehicle speed in most urban centres may lead to low carbon emissions and can also lead to increased rate of accidents. According to the world health organisation, young people lead in the 1.1 million globally estimated traffic deaths every year. Of this figure, the vast majority of victims are bicyclists and pedestrian from developing countries. In 1997, Bogota had 2 to 3 traffic related deaths every day. This was the highest in Latin America, even though it has now dropped to 1-2 due largely to development of walking and bicycling infrastructure. In April 2011, WHO also published road traffic accident death rate that showed Colombia reached 7,586 or $4.41 \%$ of total deaths (WHO, 2011). Most public discussions on transport problems often focussed on air pollution and its impacts on health. This is because of the palpable and deleterious effects of air pollution. Sustainable transportation is therefore not possible without non-motorised transport. The critical role of non-motorised transit has been documented (Banister, 2000; Mohan \& Tiwari, 1999; Wey \& Chiu, 2013; Yazid, Ismail, \& Atiq, 2011). Consequently, the need for the supporting infrastructure for these modes of travel, the perception of users and potential for use is even more challenging. Therefore, the motivation for use and potential of bicycle commuter trips is unknown.

Essentially therefore, it is neither true that Bogota is not without traffic congestion as a developing economy, nor do we expect that all residents have equal access to all modes of urban transport. The corollary is that the proportion of urban residents with access to non-motorised transport is yet unknown. It is also yet unknown what has been the motivation for use and potential of NMT especially bicycling. This further raises the question of perception of satisfaction with this mode of transport. This is even more puzzling as the city of Bogota has recently undergone major transport revolution with the development of 
ROMANIAN JOURNAL

OF TRANSPORT INFRASTRUCTURE

Inah Eteng OKON, Carlos A. MORENO

Bicycle level of service model for the cycloruta, Bogota, Colombia

Transmilenio and Cicloruta for bus rapid transit and bicycling respectively. It is on the basis of these that the study seeks to examine the bicycle level of service based on the satisfaction level of cyclists. However, no single method has so far gained universal recognition in achieving results on satisfaction level. Different methods seem to produce different results when applied in the same place and in different times. This study will therefore apply several methodologies provided in earlier studies on bicycle LOS (Guttenplan, 2003; Jensen, 2007;Landis, 1997; Landis, 2001; Jensen, 2007; Landis et al., 1997; Landis, Vattikuti, Ottenberg, McLeod, \&Guttenplan, 2001). This is because these have wider acceptance and have been adopted with modifications in the highway capacity manual (HCM, 2000). Modifications shall also be offered where necessary to reflect specific objectives of the study, local travel and infrastructure circumstances of the study area. This is in a view to developing acceptable methodology for the study area.

The study was set up in the "Sabana de Bogotá", the capital of Colombia, usually referred to as a 'plateau'. It is about 2,640 meters above sea level, located in South America, and has an average temperature of $17^{\circ} \mathrm{C}$. It is just at the foot of two important mountains, Cordillera Mountains Guadalupe and Monserrate, and its borders are Panama in the north-west, Venezuela in the north-east, and Ecuador, Peru and Brazil in the south. It has been geologically proven that this land once existed as a lake which is attested to by the Homedale's wetlands. The city has an approximated area of 1,775.98 square kilometres (33,000 acres) and a population of 7.2 million inhabitants, 15 percent of which is the total population of Colombia (MEHTP, 2010).

\section{LITERATURE REVIEW}

There is an increasing growth in the body of literature from empirical research that examines the influence of infrastructure on bicycle transportation. However, some of these researches are limited by the range of infrastructure being studied perhaps due to the multiplicity of factors which affect bicycling. For example, one of the bicycle studies conducted in Australia revealed high likelihood for bicycling by people who agreed that there were bicycle tracks along their travel route and existence of possible short cuts between their origin and destinations (Titze, Stronegger, Janschitz, \&Oja, 2008). This likelihood is twice that, compared with those whose residence and trip purpose is not served by such tracks. Consequently, a revealed preference survey of bicyclists in Texas confirmed a strong positive relationship between respondents' overall rating of bicycle facilities and the frequency of commuting with bicycle (Sener, Eluru, 
ROMANIAN JOURNAL

OF TRANSPORT INFRASTRUCTURE

Inah Eteng OKON, Carlos A. MORENO

Bicycle level of service model for the cycloruta, Bogota, Colombia

\&Bhat, 2009). Conversely, Sisson, Lee, Burns, and Tudor-Locke (2006) did not observe a significant relationship between rating for bicycle commuting by elementary school pupils and number of parked bicycles in school, but however, it concluded that other factors such as individual characteristics, type of school and social class can influence cycling to school.

A measure of this bike-friendliness in terms of users' satisfaction differs from country to country and from city to city. This is due to different socioeconomic, cultural and technological development, weather and topographic conditions, driving orientation and most importantly different satisfaction levels by residents across cities. This is perhaps why there have not been any statistically calibrated models for assessment of the satisfaction from nonmotorised transit commuters. Though at city levels, several attempts have been made to develop measures and standards for assessing non-motorised users' satisfaction. For instance, Dixon (1996) used the segment as a unit of analysis to develop a bicycle and pedestrian level of service performance measures in Gainesville, Florida as a congestion management plan.

From the user's perspective, Kang and Lee (2012) similarly developed a bicycle level of service for South Korea using 'facility, operation, intersection and safety characteristics. Their analysis using ordered logit and probit regression models revealed an increasing satisfaction with increasing width of bicycle lane. Providelo and da PenhaSanches (2011) on the other hand used successive interval analysis to develop a level of service for medium-size Brazilian cities that describes the level of satisfaction from bicycle infrastructure. Moreover, in their 'real-time human perceptions' study of American cities towards a bicycle level of service, Landis, Vattikuti, and Brannick (1997) mathematically expressed for road segments, basic traffic conditions that influence bicyclists' level of service perceptions. Accordingly, basic variables of the equation developed include, per-lane motor vehicle traffic volume, speed of motor vehicles, traffic mix, potential cross-traffic generation, pavement surface condition and width for bicycling.

The bicycle safety index rating (BSIR) is one of the first attempts to evaluate comfort and safety level of bicyclists using mathematical models (Davis, 1987). With no major changes, the Broward County, Florida adopted David's Roadway Segment Index portion of the BSIR. They renamed it roadway condition index (RCI) to assess the perception of bicycle suitability on major streets and arterials using coloured maps which were used to code existing or proposed bicycle suitability for major arterials (Eddy, 1996). The concept of 
ROMANIAN JOURNAL

bicycle stress level (BSL) was used to relate bicyclists' perception of satisfaction on specific roadway geometry and traffic conditions (Sorton \& Walsh, 1994). The Bicycle Compatibility Index (BCI) was proposed to evaluate 'cyclingfriendly environment' by estimating the quality of streets from rated grade levels of ' $A$ ' for highly compatible and ' $F$ ' for highly incompatible for cycling, and nine other variables (Harkey et al., 1998). The interaction hazard score (IHS) was developed to evaluate bicycle suitability in some urban areas of the United States of America, including: 'Birmingham, Alabama; Charlotte-Mecklenburg, North Carolina; Philadelphia, Pennsylvania; Tampa, Florida; and many others' (Landis, 1994, 1996). The Bicycle Level of Service (BLOS) is the outcome of research to validate the IHS (Landis et al., 1997). In doing this, they employed about 150 bicyclists to reflect diverse cycling experiences, ages and socioeconomic characteristics to ride round 30 distinctly selected roadway segments in Tampa, Florida. Okon, Brussel, van Den Bosch, Moreno, and van Maarseveen (2018) had accordingly provided a methodology for the estimation of BLOS in Bogota based on satisfaction data from respondents based on video clips of road segments. Other geometry, physical and operational characteristics of transportation in Bogota all formed major components in modifying the models for estimating satisfaction based on the use of the Cicloruta. Ordered choices were modelled using statistical techniques in SPSS and visualisation in ArcGIS environments.

\section{METHODOLOGICAL APPROACH}

Two pilot surveys (Enschede and Bogota) were initially carried out to ascertain the validity, and operational feasibility of our methodology. Different layers of data were used in this study, principal among which were perceptions rating data for both segments and intersections; geometric, physical and operational characteristics of road infrastructure based on both measurement and observation data.

\subsection{Video production/editing}

Segment videos were produced at different times/days of the week. Some sampling criteria include land use characteristics, trails, Ciclocarrils and Ciclovia (Sunday cycling). Each segment was filmed for 20-40 seconds while riding a bicycle at a speed of about $10 \mathrm{~km} / \mathrm{h}$ using a camera strapped, at an angle of 45 degrees, on the head (see figure 1). Curb lane variables such as bicycle pathway widths, curb lane motorised volume $(\mathrm{veh} / \mathrm{h})$ and vehicle speed $(\mathrm{km} / \mathrm{h})$, bicycle 
ROMANIAN JOURNAL

volume on segment and median width were recorded in addition to secondary data. During editing, videos were reduced to between 10-16 seconds and an instant 'repeat mode' of same time to allow review by participants.

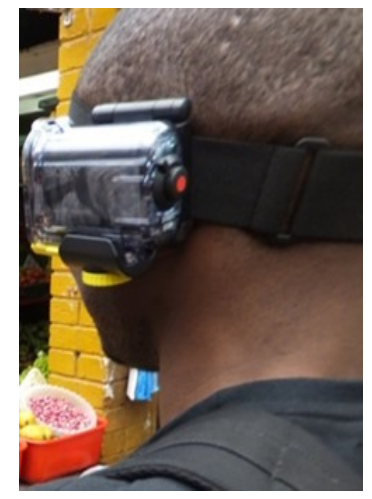

Figure 1: Position of camera during field data collection

All segments and intersections were also appropriately named at the beginning of each video and a 5 seconds break was introduced between intervals of successive videos.

\subsection{Video and satisfaction rating surveys}

Many researches have employed the video technique for bicyclist and pedestrian studies since the late 1980s after Whyte (1988) pioneered the use of film to record pedestrian behavior in New York. Jensen (2007) employed the use of a Steadicam camera in his study of "pedestrian and bicyclist level of service on road way segments in Copenhagen' and later showed it to stakeholders for rating. In this study, a bicyclist LOS questionnaire (Spanish translation) was administered to respondents in the study area for socio-economic data and ratings of videos.

Whereas the method has the perceived weakness to reflect fatigue, this may not constitute a large error since it takes about 16 minutes for the entire survey. The strength of this approach includes the ability to reach a wider response group with minimal risks; more cost effective than having to interview each respondent on site; and the ability to obtain relevant information on satisfaction level per road category. The choice of segment is due to the need to ensure uniform demand, control and geometry of the road. This, in real situations, may be difficult along a road with more than one intersection; therefore, different criteria were adopted to guide the choice of segments to 
ROMANIAN JOURNAL

OF TRANSPORT INFRASTRUCTURE

Inah Eteng OKON, Carlos A. MORENO

Bicycle level of service model for the cycloruta, Bogota, Colombia

reflect different motorised and non-motorised transport characteristics based on earlier works cited in previous sections.

\section{DATA AND ANALYTICAL TECHNIQUES}

Different methods of estimation of LOS models exist. For example, Jensen (2007) applied the ordinary generalised linear models (GLMs), cumulative logit models (CLMs), and ordinary probit models (OPMs) to develop bicycle and pedestrian models in his Copenhagen study. Hankey et al. (2012) on the other hand employed both ordinary least square (OLS) and maximum likelihood estimation (MLE) of the regression statistics to estimate models of bicycle and pedestrian traffic in Minneapolis. Similarly, Providelo and da Penha Sanches (2011) used the method of successive intervals to define traffic characteristics based on priority of users and potential users to evaluate bicycle infrastructure in Brazilian medium-sized cities. These and other studies form the background for our choice of analytical techniques.

To evaluate the level of satisfaction of bicyclists in this study, a statistical method with the capabilities for choice ordered modelling involving ordered discrete data was used. Using the Genlin procedure in SPSS, ordered probit logit was fitted in the generalized linear models (GLMs). This allows the fitting of ordinal outcomes, such as perception of LOS as rated by our survey participants based on video experiment. It is an extension of ordinal least squares regression that generalizes linear regression and thus allows the linear model to be related to the dependent variable (in our case the overall rating of segments). It is a multinomial probability distribution with cumulative logit as link function. We can therefore define an unobserved variable, $\mathrm{z}$, to derive ordered probabilities which enable us to define our BLOS rankings. These rankings exist as a linear function with an observation, $\mathrm{n}$, in which:

$$
\mathrm{zn}=\beta \mathrm{Xn}+\varepsilon \mathrm{n},
$$

where $n$ is the number of participants' rating, in this case, 1,360 ratings of 16 segments and 680 ratings of 8 intersections; $X$ is defined as a vector variable used to determine LOS; $\beta$ is a vector of parameters estimate; and $\varepsilon$ is an independent random disturbance term. when we remove the subscript $n$ from eqn (1) to simplify it and convert LOS to numerical scale, that is, from A-F or 1-6, [34] the estimate for the probit model implies that:

$$
\begin{aligned}
& \mathrm{y}=1 \text { if } \mathrm{z} \leq 0 \\
& \mathrm{y}=2 \text { if } 0<\mathrm{z} \leq \mu 1 \\
& \mathrm{y}=3 \text { if } \mu 1<\mathrm{z} \leq \mu 2
\end{aligned}
$$




$$
\begin{aligned}
& y=4 \text { if } \mu 2<z \leq \mu 3 \\
& y=5 \text { if } \mu 3<z \leq \mu 4 \\
& y=6 \text { if } z \geq \mu 4,
\end{aligned}
$$

where $\mu=$ estimable parameters (thresholds) used to categorise observed variable $y$ and estimate $\mu \& \beta$ jointly. If $\varepsilon$ in eqn (1) satisfies the assumption of independent normal distribution in all observations with $0 \& 1$ mean and variance respectively, an ordered probit model results with the selection probabilities below:

$$
\begin{aligned}
& \mathrm{P}(\mathrm{y}=1)=\Phi(-\beta \mathrm{X}) \\
& \mathrm{P}(\mathrm{y}=2)=\Phi(\mu 1-\beta \mathrm{X})-\Phi(-\beta \mathrm{X}) \\
& \mathrm{P}(\mathrm{y}=3)=\Phi(\mu 2-\beta \mathrm{X})-\Phi(\mu 1-\beta \mathrm{X}) \\
& \mathrm{P}(\mathrm{y}=4)=\Phi(\mu 3-\beta \mathrm{X})-\Phi(\mu 2-\beta \mathrm{X}) \\
& \mathrm{P}(\mathrm{y}=5)=\Phi(\mu 3-\beta \mathrm{X})-\Phi(\mu 3-\beta \mathrm{X}) \\
& \mathrm{P}(\mathrm{y}=6)=1-\Phi(\mu 4-\beta \mathrm{X}),
\end{aligned}
$$

where $\Phi($.$) is defined as the cumulative distribution function of standard normal$ distributionor simply represents the usual probit function.

Since 16 observations for segments are generated by each of the participants, there is therefore likelihood for these observations to share unobserved effects. This violates the independent disturbance assumption in equation (1). We therefore adopt the traditional random effects to address this occurrence. It is where an individual-specific term piis included in order to rewrite equation 1 , thus:

$$
\mathrm{zn}=\beta \mathrm{Xic}+\varepsilon \mathrm{ic}+\varphi \mathrm{i}
$$

where subscript I denotes the index of individual participant; subscript $c$ as index of video clips; while all other terms are as earlier defined (Kang et al., 2013; Shafizadeh \& Mannering, 2006; Tan \& Irfanoglu).

In this study, a generalised random parameter approach is preferred to the traditional random effect. This is because of the very subjective nature of satisfaction or comfort, in which our rating data is obtained. In this sense, the model is generalised for each of the 85 participants to have its own $\beta \mathrm{i}$. Traditional random effect method would have assumed participants get their own constant but constrained to have values in $\beta$ the same. For each respondent therefore, $i, \beta i$ is estimated as a random and fixed term, written as:

$$
\beta=\beta+\text { wi }
$$

where $\beta i$ is a vector of specific individual parameters, wi is disturbance term for the random distribution.

However, maximum likelihood estimation using Halton draws can be used to estimate this random parameter, and has been proved to be an efficient sampling method (Bhat, 1999; Fridstrøm, Ifver, Ingebrigtsen, Kulmala, \& 
ROMANIAN JOURNAL

OF TRANSPORT INFRASTRUCTURE

Inah Eteng OKON, Carlos A. MORENO

Bicycle level of service model for the cycloruta, Bogota, Colombia

Thomsen, 1995; Greene \& Hensher, 2009; Qi, Smith, \& Guo, 2007; Washington et al., 2011). Indeed, one of the advantages of GLMs is that the structure of the linear predictor isthe familiar structure of a linear model' (Nelder \& Wedderburn, 1972).

\section{SEGMENT BICYCLE LEVEL OF SERVICE MODEL(SegBLOS)}

Initial development and calibration of BLOS started at the roadway segment level. The methodology for the various operations in the previous section is summarised in figure 2 . 
ROMANIAN JOURNAL

OF TRANSPORT INFRASTRUCTURE

Inah Eteng OKON, Carlos A. MORENO

Bicycle level of service model for the cycloruta, Bogota, Colombia

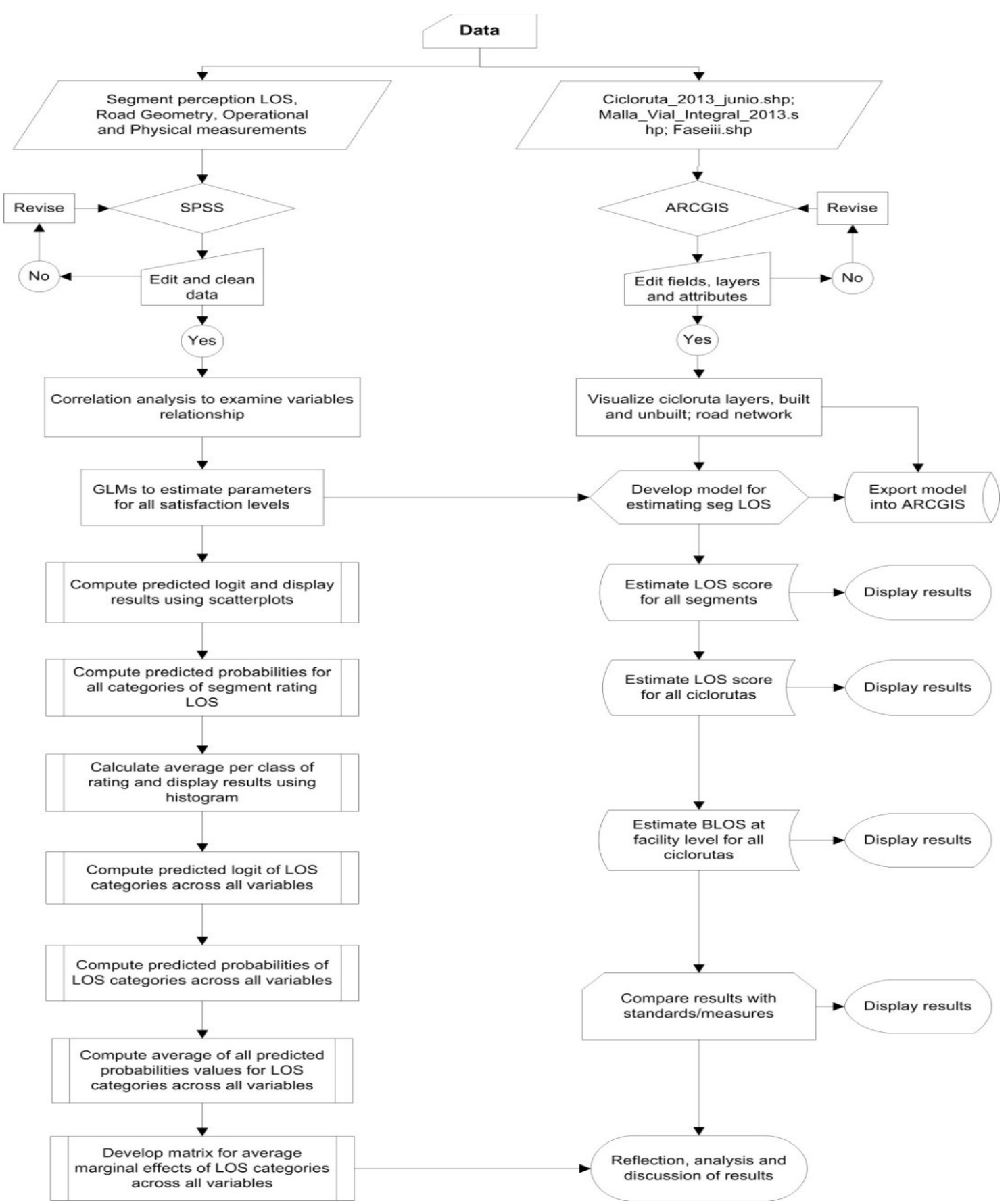

Figure 2. Methodology for segment BLOS estimation

According to the HCM (2000) 'the segment levels of service for a given direction of travel are combined into an overall directional level of service for the study section of street by taking a length weighted average of the segment levels of service for the analysis direction'. Our segment LOS is defined as BLOS score for every named segment. The estimated model is used to calculate 
ROMANIAN JOURNAL

OF TRANSPORT INFRASTRUCTURE

Inah Eteng OKON, Carlos A. MORENO

Bicycle level of service model for the cycloruta, Bogota, Colombia

LOS score for each segment and Cicloruta in ArcGIS. A matrix for average marginal effects of the influence of individual variable on the probability of level of service by Cicloruta users is generated. We further aggregate our segment BLOS (about 584 segments) into Ciclorutas (71) based on their name ID. It is important to note that different segments of the Cicloruta share similar names irrespective of their categorisation. To make our scores amenable for facility BLOS, therefore, we averagedall scores of similar Ciclorutas using:

$\mathrm{AVBLOS}_{\text {segment }}=\sum \mathrm{BLOS}_{\text {segment }} 1+2, \ldots \ldots, \mathrm{n} / \mathrm{N}$

Where AVBLOS segment $=$ average BLOS score for Cicloruta sharing similar name ID; $n=$ referring to nth number of Ciclorutas; and $N=$ total number of segments.

Estimation of LOS at all three levels is matched against LOS scores shown in Table 1 . This is as according to the highway capacity manual, a modification of Landis (1994) and Landis et al. (2003). Our initial rating values and other measurement data are now converted into parameter estimates and coefficients and are therefore comparable to the table values (Table 1). At the facility level therefore, about 71 Ciclorutas have their BLOS estimated to provide a methodology for future estimation, facility maintenance and upgrade of the cycling network.

\subsection{Study demographics}

Analysis of the influence of socioeconomic characteristics of research participants reveals no positive relationship on rating of satisfaction level at 0.05 level of significance for segments. However, individual socioeconomic variable like gender and experience of cyclists show great tendencies. For example, female tend to rate segments lower than their male counterparts; while experienced cyclists revealed higher satisfaction in their rating of both segments and intersections than inexperienced cyclists (Table 2). The influence of the age of the participant differs in segments and intersection. For example, in segment rating, participants younger than 35 years.

Similarly, there is more male (63.5 per cent) participation in the survey than female (36.5 per cent), while across age distribution, the data revealed a very high (84.7 per cent) participation of subjects between 18-35 years. This may be explained by the choice of universities as preferred areas for survey due to the enabling environment they provide including classrooms equipped with projectors and willingness of students to participate. This was without any form 
ROMANIAN JOURNAL

OF TRANSPORT INFRASTRUCTURE

Inah Eteng OKON, Carlos A. MORENO

Bicycle level of service model for the cycloruta, Bogota, Colombia

of material motivation, reward or lack of time as expressed by some staff in many government ministries who were approached for this survey. More participants fall within ages of $18-35$ in both male (88.9 per cent) and female (77.4 per cent) while bicycle ridership also revealed more riders in male (75.9 per cent) than in female (58.1 per cent). Overall bicycle ridership in the study area showed that 69.4 per cent ride bicycle in the city while 30.6 per cent do not.

A chi-square statistics of these relationships above shows an $X^{2}$ value of $1.281^{\mathrm{a}}$, 2 degree of freedom and a $\mathrm{p}$-value of 0.734 which is however greater than our confidence level of 0.05 for gender and ridership (Table 3). We therefore conclude that the null hypothesis should be accepted, that there is not enough evidence to suggest that any differences between gender use of bike in Bogota is for any reason other than chance (example, sampling error and so on). These findings also hold true for independent male and female bicycle ridership with $\mathrm{p}$ value of 0.343 and 0.153 respectively, which are both greater than our confidence value of 0.05 . We conclude that despite observed differences in this data, there is not sufficient evidence to prove its occurrence other than chance probably due to sampling error.

Table 1. LOS scores (after HCM, 2012)

\begin{tabular}{lll}
\hline LOS & Score & Description \\
$\mathrm{A}$ & $\leq 2.00$ & Excellent \\
$\mathrm{B}$ & $>2.00-2.75$ & Very good \\
$\mathrm{C}$ & $>2.75-3.50$ & Good \\
$\mathrm{D}$ & $>3.50-4.25$ & Fair \\
$\mathrm{E}$ & $>4.25-5.00$ & Poor \\
$\mathrm{F}$ & $>5.00$ & Very poor \\
\hline
\end{tabular}


ROMANIAN JOURNAL

OF TRANSPORT INFRASTRUCTURE

Inah Eteng OKON, Carlos A. MORENO

Bicycle level of service model for the cycloruta, Bogota, Colombia

Table 2. Satisfaction rating by research participants for segments

\begin{tabular}{|c|c|c|c|}
\hline $\mathrm{s} / \mathrm{n}$ & Group of participants & $\begin{array}{l}\text { Segment ratir } \\
\text { Number ratin }\end{array}$ & verage \\
\hline 1 & All participants & 1,360 & \\
\hline 2 & House type & & \\
\hline & Detached & 192 & 2.80 \\
\hline & Terraced & 192 & 2.74 \\
\hline & Flat & 800 & 2.51 \\
\hline & Student hostel & 112 & 2.78 \\
\hline & Other & 32 & 1.81 \\
\hline 3 & Age & & \\
\hline & Equal or less $35 y$ rs & 1184 & 2.68 \\
\hline & Greater than $35 y$ rs & 176 & 1.99 \\
\hline 4 & Gender & & \\
\hline & Female & 496 & 2.77 \\
\hline & Male & 864 & 2.54 \\
\hline 5 & Number of trips & & \\
\hline & $<5$ trips/week & 944 & 2.63 \\
\hline & $5-10$ & 144 & 2.28 \\
\hline & $10+$ & 256 & 2.71 \\
\hline 6 & Bike use/week & & \\
\hline & 0 & 288 & 2.79 \\
\hline & 1-2days & 256 & 2.54 \\
\hline & $3-5$ & 528 & 2.58 \\
\hline & $6+$ & 256 & 2.54 \\
\hline 7 & Number of km bike/week & & \\
\hline & $<10$ days/week & 560 & 2.69 \\
\hline & $10-15$ & 160 & 2.73 \\
\hline & $16-29$ & 144 & 2.44 \\
\hline & $39-45$ & 80 & 2.48 \\
\hline & $46+$ & 368 & 2.57 \\
\hline 8 & Effect of weather on bike & 208 & 260 \\
\hline & No effect & 1152 & 2.61 \\
\hline 9 & Yes effect & & \\
\hline & Experience in cycling & 976 & 2.20 \\
\hline & Inexperienced & 320 & 2.67 \\
\hline & Experienced & & \\
\hline
\end{tabular}


ROMANIAN JOURNAL

OF TRANSPORT INFRASTRUCTURE

Inah Eteng OKON, Carlos A. MORENO

Bicycle level of service model for the cycloruta, Bogota, Colombia

Table 3. Chi-Square tests of bicycle ridership in the city, age and gender of research participants

\begin{tabular}{lllll}
\hline Gender of participant & Value & df & Asymp. Sig (2-sided) \\
Male & Pearson Chi-Square & $2.140^{\mathrm{b}}$ & 2 & .343 \\
& Likelihood Ratio & 3.536 & 2 & .171 \\
& Linear-by-Linear Ass. & 1.884 & 1 & .170 \\
\multirow{5}{*}{ Female } & N of Valid Cases & 54 & & .153 \\
& Pearson Chi-Square & $3.758^{\mathrm{c}}$ & 2 & .147 \\
& Likelihood Ratio & 3.836 & 2 & .180 \\
& Linear-by-Linear Ass. & 1.797 & 1 & .734 \\
\multirow{5}{*}{ Total } & N of Valid Cases & 31 & & .677 \\
& Pearson Chi-Square & $1.281^{\mathrm{a}}$ & 2 & .974 \\
& Likelihood Ratio & 1.524 & 2 & \\
\hline & Linear-by-Linear Ass. & .001 & 1 & \\
& N of Valid Cases & 85 & & \\
\hline
\end{tabular}

The experience of cyclists in the city was also investigated. While the best cycling conditions are desirable by all cyclists irrespective of how long one has been riding, the author observed that this gives an indication of high level of confidence exhibited by cyclist at worst case scenarios and not necessarily the level of experience. This is more so that even those who responded as not using bike in the city also answered a question on experience. For example, while about $69.4 \%$ of the study population uses bike in the city, $71.8 \%$ of the entire study population (not of bike users) are inexperienced while $23.5 \%$ indicated that they could ride under the worst conditions. Moreover, of these inexperienced cyclists, $43.5 \%$ and $28.2 \%$ are males and females respectively. Expectedly, 17.6 and 5.9\% represent experienced males and female respectively, which is reflective of the distribution of our sample size $(63.5$ and $36.5 \%$ male and female respectively) and not necessarily true in Bogota even though it has been observed that males and active population have the likelihood to endure difficult bicycle riding conditions.

\subsection{Perception bicycle level of service}

A six-point rating system ranging from 1 as highly satisfied to 6 as highly dissatisfied was used to assess the LOS score for perceived level of satisfaction of participants. This was based on video clips of 16 sampled segments whose choices were based on criteria discussed under methodology. These segment videos were produced to represent a wide range of physical, operational and 
ROMANIAN JOURNAL

OF TRANSPORT INFRASTRUCTURE

Inah Eteng OKON, Carlos A. MORENO

Bicycle level of service model for the cycloruta, Bogota, Colombia

geometric characteristics of the Cicloruta such as width of cycle lane/track, separation from the curb lane, availability of trees/grasses/benches, vehicular volume and speed in adjacent arterial, pedestrian flow, and so on. A total of 1,360 scores were obtained for segments by 85 participants across different variables that define in qualitative terms the level of satisfaction as viewed in the video (Table 4). Data in the table shows that while average percentages for level of satisfaction in segments decreases downwards from highly satisfied to highly dissatisfied, the reverse is the case for average intersection rating.

A cross section of sampled segments for this study is shown in figure 3 and thus reveals different categorisation in terms of quality, land use and physical conditions of the Cicloruta. Participants rated Calle 26 (Las Aquas-Av. El Dorado) with a high LOS score (Table 5). It has a width of about 2.25-2.50m, looks more or less like a trail with trees and reasonably separated from the highway with barriers. Participants also considered the security advantage the location of this Cicloruta provides, more so that it is separated from pedestrian use unlike many other Ciclorutas. The major challenge of this Cicloruta is the lack of access and egress since it is sandwiched between an 8-lane highway. Three samples were drawn from this Cicloruta, including, Cicloruta (bike path), ciclovia (Sunday bike lane) and tunnel. They all scored differently and therefore, an average score is obtained (1.71). Centro Internacional (Canal Salitre-Juan Amarillo-S) was also rated highly unlike Canal Arzobispo (Canal Salitre-Juan Amarillo-N), an average LOS score is also obtained (2.69). The high satisfaction level is not unexpected as the infrastructure is new and located around the CBD with potential for high use. The LOS rating of Canal Arzobispo reveals participants' expression of little satisfaction from the use of this cycle lane. Carrera 7 (KR 11-13-S) was given a high rating unlike Carrera 13 (KR 11$13-\mathrm{N}$ ), thus giving an average LOS of 3.03. In the same vein, Puente Avenida 68 Americas (NQS H/way (roadway) on the other hand, is a stretch that links two Ciclorutas, Calle 13 and the Americas (collectively called NQS). This is not a Cicloruta, but was deliberately included in the survey to expose the apparent dangers that cyclists are confronted with by the frequent Cicloruta dead ends. An average LOS score 4.85 is obtained, having considered the rating of Avenida Americas CostadoNorte (NQS). 
ROMANIAN JOURNAL

OF TRANSPORT INFRASTRUCTURE

Inah Eteng OKON, Carlos A. MORENO

Bicycle level of service model for the cycloruta, Bogota, Colombia

Table 4. Satisfaction rating for 16 road segments and 8 intersections

\begin{tabular}{lll}
\hline Nominal scale & Ordinal scale & Segments (Count \& \%) \\
1 & Highly satisfied & $326(25.5)$ \\
2 & Moderately satisfied & $352(27.5)$ \\
3 & A little satisfied & $235(18.4)$ \\
4 & A little dissatisfied & $126(9.9)$ \\
5 & Moderately dissatisfied & $129(10.1)$ \\
6 & Highly dissatisfied & $110(8.6)$ \\
Total & & $\mathbf{1 3 6 0}(\mathbf{1 0 0})$ \\
\hline
\end{tabular}

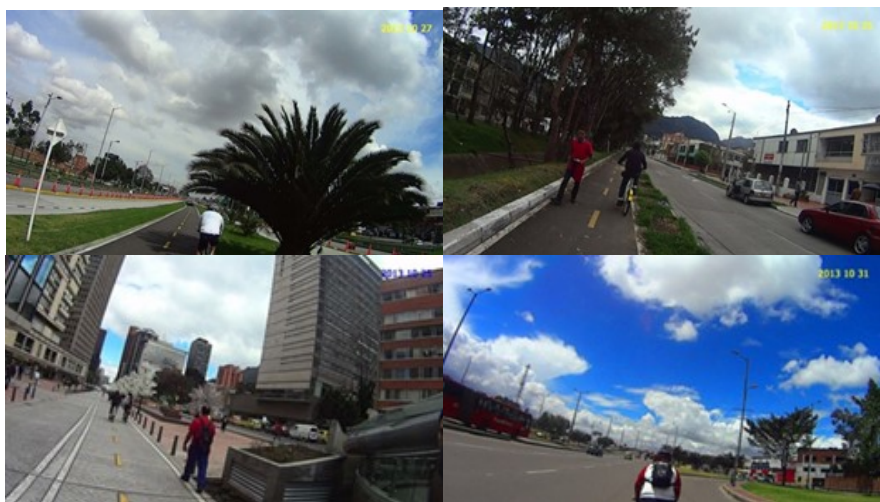

Figure 3: Sampled segments in Calle 26 with an average perception LOS=1.4; Canal Arzobispo(LOS $=3.3)$; Centro Internacional( $\operatorname{LOS}=2.1)$; and Puente Avenida 68 Americas $(\mathrm{LOS}=5.3$ ) 
ROMANIAN JOURNAL

OF TRANSPORT INFRASTRUCTURE

Inah Eteng OKON, Carlos A. MORENO

Bicycle level of service model for the cycloruta, Bogota, Colombia

Table 5. Segments that constitute study area and their average perception LOS

\begin{tabular}{|c|c|c|c|c|}
\hline \multicolumn{5}{|c|}{ scores } \\
\hline Segment (survey) name & Cicloruta name & No of seg & Av.LOS & Description \\
\hline Calle 13 & Av. Jimenez-Americas & 18 & 4.27 & $\mathrm{AD}$ \\
\hline Carrera 7 & KR $11-13$ & 1 & 1.79 & HS \\
\hline Cicloruta Av. El Dorado & Las Aquas-Av. El Dorado (tunel) & 13 & 2.01 & HS \\
\hline Calle 26 & Las Aquas -Av. El Dorado (ruta) & 13 & 1.43 & HS \\
\hline Calle 26 (ciclovia) & Las Aquas -Av. El Dorado (c- & 13 & 1.71 & HS \\
\hline Canal Arzobispo & via) & 17 & 3.27 & MS \\
\hline Paerque Simon Boliva & Canal Salitre-Juan Amarillo (n) & 13 & 1.87 & HS \\
\hline Calle 53 & Simon Boliva (trails) & 27 & 1.7 & HS \\
\hline Carrera 50 (ciclocarril) & Cl 100-Av 68 (trail) & 38 & 3.77 & MS \\
\hline Carrera 13 & AvenidaBoyaca & 18 & 4.11 & $\mathrm{AD}$ \\
\hline Centro Internacional & KR 11-13 (norte) & 17 & 2.1 & MS \\
\hline AvenidaPepeSeirra & Canal Salitre-Juan Amarillo (s) & 3 & 2.0 & HS \\
\hline Alameda El Porvenir & AvenidaPepeSeirra & 19 & 1.75 & HS \\
\hline Carrera 71d & Av. TintalPorvenir & 9 & 4.48 & $\mathrm{AD}$ \\
\hline Av. Americas Costado- & Av. Agoberto Mejia & 23 & 2.63 & MS \\
\hline $\mathrm{N}$ & NQS & 23 & 5.42 & MD \\
\hline $\begin{array}{l}\text { Puente } \\
68 x \text { Americas }\end{array}$ & NQS H/way (roadway) & & & \\
\hline
\end{tabular}

Based on these perception ratings by participants, it was possible to extrapolate satisfaction across all 70 Ciclorutas. This was done by comparing the basic infrastructure (physical) characteristics of sampled segments with other Ciclorutas. These physical characteristics include width of cycle lane, location of lane, kind (lane, track or trail) and urban place (CBD as urban orother urban). Measurements, physical observations during field work and relevant street maps provided the author useful insight into major characteristics of Ciclorutas. Since there was no rating as highly dissatisfied, all non-constructed Ciclorutas were assigned the rating. This is also based on the author's experience as the satisfaction level from these Ciclorutas is obviously the lowest. Table 6 shows these categories based on level of satisfaction, which then enables us to apply model 1 on the data set in an ArcGIS environment. A constant value of 1 is used when segment satisfy variable best condition and 1.5 when it does not. This is based on the 6 point like where the lowest value represents the best condition and highest value otherwise (in this case $1,1.1 \ldots, 1.5$ ). This helps to give an individual segment an LOS score based on its characteristics, before averages at Cicloruta level are solved. Figure 4 presents a graphic illustration of some of these segments and their accompanying average perception LOS scores. 
ROMANIAN JOURNAL

OF TRANSPORT INFRASTRUCTURE

Inah Eteng OKON, Carlos A. MORENO

Bicycle level of service model for the cycloruta, Bogota, Colombia

Field observations also revealed that some segments were not defined necessarily by intersection but by other factors such as a complete cycleof trail, termination of constructed Cicloruta, and so on. The result may may be related to the fact that the survey was taking place mostly during the peak period and the level of dissatisfaction participants already have about segments prior to the survey. Based on our video survey and extrapolation of data across the study area we thus obtain our perception BLOS as shown in figure 6. This enables for the substitution of satisfaction levels in the equation to estimate our BLOS.

Table 6. Ciclorutas according to level of satisfaction

\begin{tabular}{|c|c|c|c|}
\hline HS & MS & & AS \\
\hline LAS AQUAS-AV.EL DORADC & CANAL & ALITRE-JUAN & KR 11-13 \\
\hline CL 100-AV 68 (TRAIL) & AMARILLO & & AV FERNANDO \\
\hline AV. TINTAL PORVENIR & AV 1 DE MAYO & & MAZUERA \\
\hline SIMON BOLIVA (TRAILS) & AV. CL 6 & & AV FERROCARRIL DEL \\
\hline AVENIDA PEPE SEIRRA & AVENIDA BOYAC & & SUR \\
\hline AC 63 (AV. JOSE CELESTINO & AVENIDA CALLE 1 & 27 & AV. SUBA \\
\hline MUTIS) & BANDERAS - PORI & JENIR & PARQUE TOBERÍN \\
\hline AUTOPISTA NORTE & CANAL MOLINOS & & PARQUE VILLA ALSACIA \\
\hline AV SAN BERNARDINO & CANAL RÍO FUCH & & RIO NEGRO CASTELLANA \\
\hline AV. CL 134 & CIUDAD SALITRE & & \\
\hline AVENIDA CIUDAD DE CALI & CL 170 & & \\
\hline BANDERAS - PATIOBONITO & CL 48 R SUR & & \\
\hline CANAL TORCA - AV 19 & CL 6 & & \\
\hline CIRCUITO TUNAL & CL 80 & & \\
\hline ENGATIVÁ - HUMEDAL & HOSPITAL SAN CA & RLOS & \\
\hline JABOQUE & PARQUE EL TIMIZ & & \\
\hline MEISSEN & PARQUE LA AURO & RA II & \\
\hline PARQUE TERCER MILENIO & AV KR 9 - AV CL 9 & & \\
\hline RÍO BOGOTÁ - LA GAITANA & & & \\
\hline SIMÓN BOLÍVAR (CIRCUITC & & & \\
\hline AV. VILLAVICENCIO & & & \\
\hline $\mathrm{AD}$ & MD & HD & \\
\hline JIMENEZ- & NQS & ACJAS & \\
\hline AMERICAS & AV. AGOBERTO MEJIA & AEROPUER & TO EL DORADO \\
\hline & LA CANDELARIA & AV BOSA & \\
\hline & PARQUE CL 42 SUR KR & AV CL 19 & \\
\hline & $72 \mathrm{I}$ & AV DE LA C & ONSTITUCIËN \\
\hline & & AV DE LA F & IORTUA \\
\hline & & AV EL CEN' & TENARIO \\
\hline & & AV EL TABC & \\
\hline & & AV FUCHA & \\
\hline & & AV GENER & AL SANTANDER \\
\hline & & AV JORGE & GAITÁN CORTÉS \\
\hline & & AV LA VICT & ORIA \\
\hline & & AV LAS AM & ÉRICAS \\
\hline & & AV LONGI'T & UDINAL DE \\
\hline & & OCCIDENT & \\
\hline
\end{tabular}


ROMANIAN JOURNAL

OF TRANSPORT INFRASTRUCTURE

Inah Eteng OKON, Carlos A. MORENO

Bicycle level of service model for the cycloruta, Bogota, Colombia

\begin{tabular}{ll}
\hline & \\
\hline & AV MANUEL CEPEDA VARGAS \\
& AV MARISCAL SUCRE \\
& AV. CIRCUNVALAR - AV. LOS \\
& CERROS \\
& AV. LAUREANO GÓMEZ \\
& AVENIDA CARACAS \\
& AVENIDA DEL SALITRE \\
& LA FLORIDA \\
& PARQUE LOS FUNDADORES \\
Total & RIO TUNJUELO \\
& $\mathbf{7 1}$ \\
\hline
\end{tabular}
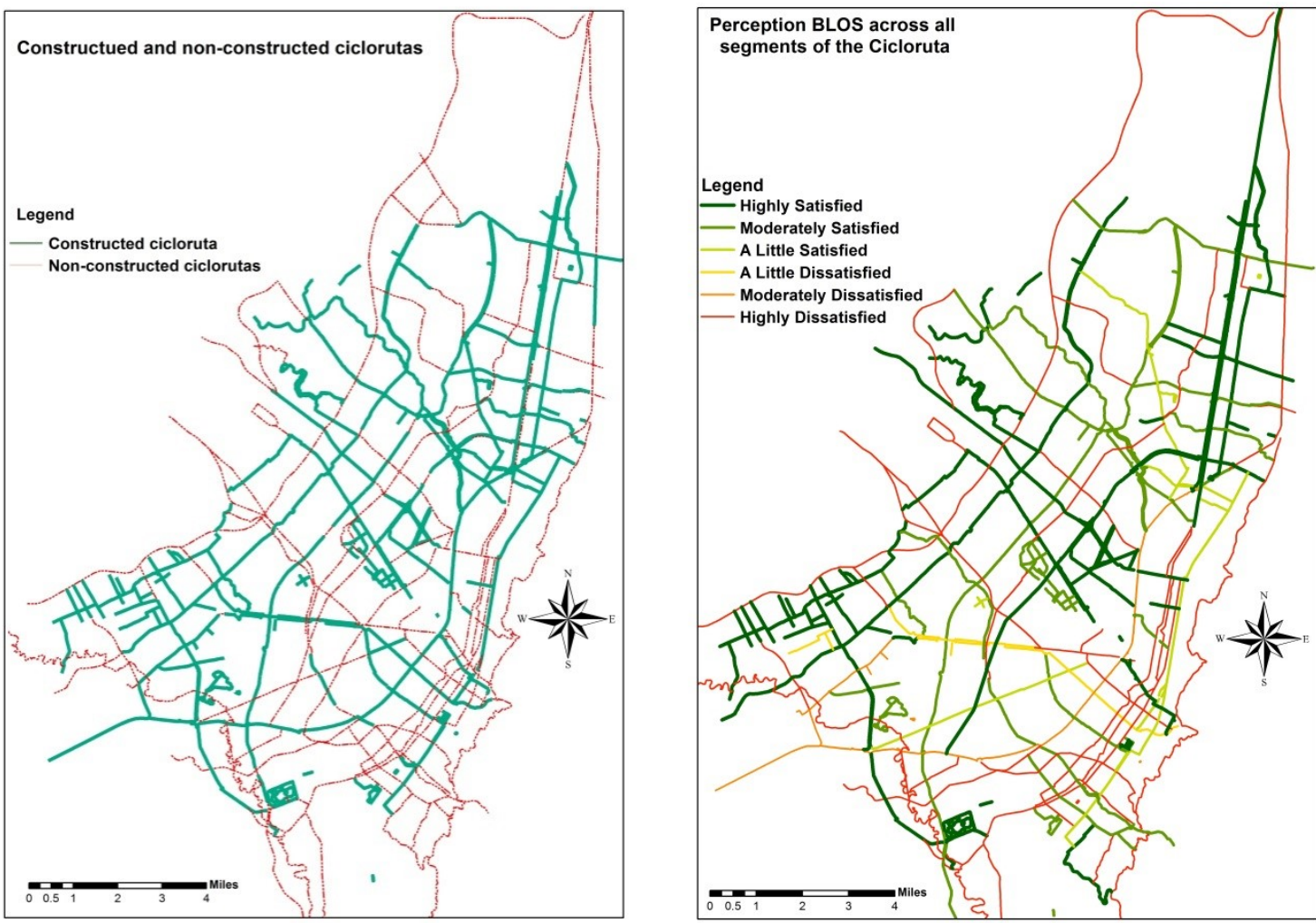

Figure 4. Constructed and un-constructed Ciclorutas; perception BLOS across the study area

\subsection{Estimation results of SegBLOS model}

Preliminary investigations showed a strong correlation between dependent variable and independent variables at 0.05 level of significance. About 1,360 ratings were used in the estimation process. The deviance (1.085) and Pearson Chi-Square (2.309) with 1,635 degree of freedom at 0.05 level of significance shows that our model provides a better fit of the data. This is because deviance 
ROMANIAN JOURNAL

is close to the value of 1 and shows a low difference from Pearson,therefore, the model is a good fit. The Omnibus test in our model compares the intercept only model to the fitted model. Likelihood Ratio Chi-Square value of .000 reveals that the fitted model is significantly different from the intercept only model, thus suggesting that the random parameter model provides a superior statistical fit than traditional random effects with over $99.99 \%$ confidence. Using equation 5, we therefore estimated parameters for each observation or variable. This result shows that parameters vary across participants. Results of the random parameters ordered probit model are shown in Table 7. They were obtained from 1,360 ratings from 16 segment videos rated by 85 participants. Positive parameters in Table 7 means that a unit change would lead to a higher probability that LOS F will be perceived, while negative parameters on the other hand means unit change in the variable leads to a higher probability that LOS A will be perceived by participants. The validity of these estimates to confirm they did not occur by chance or result of sample error was tested at 0.05 level of significance. Some of the parameters found to vary across respondents (random) included side path separation (SPS), vehicle speed (VS), motorised traffic volume, motorised traffic volume (MTV), conflicts with pedestrian (CWP), daylight, gender, and age.

Table 7. Random parameters ordered probit model of bicyclists perceived level of service (segments)

\begin{tabular}{|c|c|c|c|c|}
\hline Variable description & $\begin{array}{l}\text { B } \\
\text { (Parameter } \\
\text { est.) }\end{array}$ & $\begin{array}{l}\operatorname{Exp}(B) \\
\text { (Variance of } \\
\text { est.) }\end{array}$ & $\begin{array}{l}\text { Wald Chi- } \\
\text { Square }\end{array}$ & Sig. \\
\hline Threshold 1 & .187 & 1.205 & 1.925 & .165 \\
\hline Threshold 2 & 1.024 & 2.784 & 55.647 & .000 \\
\hline Threshold 3 & 1.601 & 4.957 & 129.666 & .000 \\
\hline Threshold 4 & 1.973 & 7.189 & 190.072 & .000 \\
\hline Threshold 5 & 2.435 & 11.416 & 279.138 & .000 \\
\hline Threshold 6 & 2.955 & 19.196 & 395.655 & .000 \\
\hline BLW $(1=<2 \mathrm{~m} ; 0>2 \mathrm{~m}=)$ & -.126 & .882 & .487 & .485 \\
\hline WOL $(1=<10 \mathrm{ft} ; 0=>10 \mathrm{ft})$ & -.451 & .637 & .189 & .663 \\
\hline PCL ( $1=$ Good; $0=$ otherwise $)$ & -.114 & .893 & .012 & .914 \\
\hline SPS ( $1=$ present; $0=$ otherwise) & .605 & 1.831 & 29.946 & .000 \\
\hline NTL $(1 \leq 2$ lanes; $0=$ otherwise $)$ & .726 & 2.066 & .486 & .486 \\
\hline $\mathrm{VS}(1 \leq 30 \mathrm{mi} / \mathrm{hr} ; 0=$ otherwise $)$ & .717 & 2.049 & 49.859 & .000 \\
\hline MTV $\quad(\leq 600$ cars $/ 15 \mathrm{~min}$ & -.381 & .683 & 10.976 & .001 \\
\hline $0=$ otherwise $)$ & 1.173 & 3.231 & 156.831 & .000 \\
\hline CWP $\quad(1=\leq 10$ & -.038 & .963 & .105 & .746 \\
\hline $0=$ otherwise) & .473 & 1.605 & 9.700 & .002 \\
\hline TB $(1=$ trees/benches/grasses; & -.026 & .974 & .180 & .671 \\
\hline
\end{tabular}


ROMANIAN JOURNAL

OF TRANSPORT INFRASTRUCTURE

Inah Eteng OKON, Carlos A. MORENO

Bicycle level of service model for the cycloruta, Bogota, Colombia

\begin{tabular}{|c|c|c|c|c|}
\hline $0=$ otherwise) & .118 & 1.125 & 3.466 & .936 \\
\hline DAYLIGHT & .005 & 1.005 & .006 & .063 \\
\hline $0=$ otherwise $)$ & -.262 & .769 & 18.219 & .000 \\
\hline RAIN (1=Rain; $0=$ otherwise) & .473 & 1.604 & 27.064 & .000 \\
\hline RIDE ( $1=$ Ride in city; & 1,360 & & & \\
\hline $0=$ otherwise) & 4.55 .322 & & & \\
\hline EXPERIENCE & $(.000)$ & & & \\
\hline $0=$ otherwise $)$ & 1773.484 & & & \\
\hline $\operatorname{GENDER}(1=$ Male; $0=$ Female $)$ & $(1.085)$ & & & \\
\hline $\mathrm{AGE}$ & 1773.484 & & & \\
\hline Number of observations & 3774.940 & & & \\
\hline Log likelihood chi-square & (2.309) & & & \\
\hline Deviance & 3774.940 & & & \\
\hline Scaled Deviance & -1257.919 & & & \\
\hline Pearson Chi-Square & 2557.839 & & & \\
\hline Scaled Pearson Chi-Square & 2558.529 & & & \\
\hline Log likelihood & 2667.359 & & & \\
\hline $\begin{array}{l}\text { Akaike's Information } \quad \text { Criteria } \\
\text { (AIC) }\end{array}$ & 2688.359 & & & \\
\hline $\begin{array}{l}\text { Finite Sample Corrected } \\
\text { (AICC) }\end{array}$ & & & & \\
\hline $\begin{array}{l}\text { Bayesian Information Criteria } \\
\text { (BIC) }\end{array}$ & & & & \\
\hline Consistent AIC (CAIC) & & & & \\
\hline
\end{tabular}

Dependent variable responses are integers ranging from 1-6 for A-F (highly satisfied-highlydissatisfied)

They are normally distributed with standard deviation significantly different from zero. We therefore conclude that they provide a more superior statistical fit to the data; even though other variables are considered for random parameters, they provide inferior statistical fit. Akaike's Information Criteria (AIC), Finite Sample Corrected AIC (AICC) and Bayesian Information Criteria (BIC) are useful statistics to compare models. Since we adopted the interaction approach in our model estimate, it is therefore not relevant to do any comparison.

Recall that our satisfaction levels ranges from 1 for highly satisfied to 6 for highly dissatisfied. Therefore, in our estimated parameters (Table 7), the probability to rate or derive a HS level increases the ordered logit by 0.187 or is exponentiated at 1.205 less likely than other levels of satisfaction. The same cannot be said about other levels of satisfaction as there are statistically significant at 0.05 confidence interval, where AS, MS, MD, AD and HD are 
ROMANIAN JOURNAL

OF TRANSPORT INFRASTRUCTURE

Inah Eteng OKON, Carlos A. MORENO

Bicycle level of service model for the cycloruta, Bogota, Colombia

respectively exponentiated at $2.789,4.957,7.189,11.416$ and 19.196 less likely than other levels of satisfaction. We therefore develop our estimation model using our parameters and factors that are statistically superior in their contribution to the level of satisfaction rating (box 1). About 15 variables comprising of 13 factors and 2 covariates were initially used in the estimation while only 7 were statistically superior to fit the model at 0.05 confidence interval (Table 7).

\section{Box 1: Model 1}

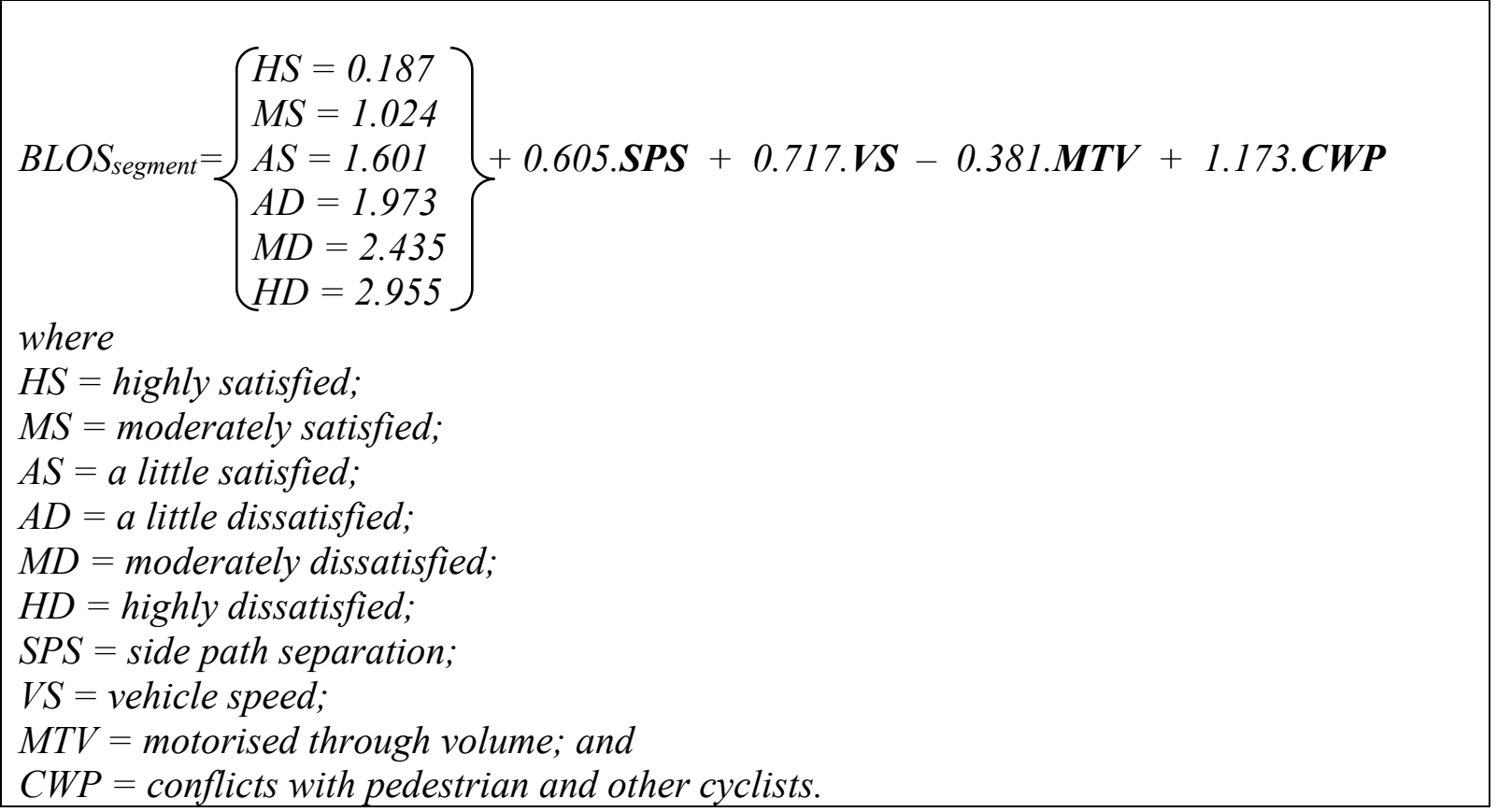

This includes 4 measurement variables (SPS, VS, MTV and CWP), 1 environmental variable (daylight), and 2 socio-economic variables (age and gender). Hybrid parameter estimation with a Maximum Fisher Scoring Iterations at 1 was carried out using Wald statistics. In estimating our model therefore, only the 4 statistically significant variables were used. These include: side path separation (SPS), vehicle speed (VS), motorised traffic volume (MTV), and conflicts with pedestrian (CWP). Gender and age showed statistical significance but could not be used in the model as they are used as covariate in the estimation process.

Daylight, however statistically significant it may be, could not be used, as it is an environmental variable whose changes are obvious, day and night. This result however underscore the preferred time of cycling in the study area which may not be unconnected with safety issues. This result does not imply that they 
ROMANIAN JOURNAL

OF TRANSPORT INFRASTRUCTURE

Inah Eteng OKON, Carlos A. MORENO

Bicycle level of service model for the cycloruta, Bogota, Colombia

are not other important factors in considering the level of participants' satisfaction as marginal effects has proved otherwise. In figure 5 results of the BLOS estimation at segment and Cicloruta (facility) level are displayed. Not much difference can be observed since scores are aggregated to grades. Most Ciclorutas adjoin the Avenida El Dorado in the west just as others in the north and south west are revealed to score B grade. No Cicloruta secured an 'A' grade in both results, which may not necessarily mean that no cyclist derives highest satisfaction level from use of specific segments of the Cicloruta, except that averages are used in the estimate.

In order to effectively apply equations 2 and 3 to estimate our predicted probabilities, initial logit scores for each category of response as well as each variable for all participants were predicted. This initial procedure of the computation of predicted logit produced a sigmoid-curve scatter plot across all BLOS category responses which look somewhat like the s-shape curvein logistic regression (figure 6). It reveals satisfaction level of participants based on unit changes in allvariables combined. Predicted probabilities were estimated based on the principles contained in equation 5using Euler's number, 2.718281828.

To validate the outcome of our BLOS segment model, we compared the perception ratings with estimated scores as shown in figure 6 . It reveals similar pattern of rating except that the estimated scores do not produce an 'A' rating. In an ideal situation for Bogota Cicloruta, the model seems tenable for evaluation of the Cicloruta infrastructure. 
ROMANIAN JOURNAL

OF TRANSPORT INFRASTRUCTURE

Inah Eteng OKON, Carlos A. MORENO

Bicycle level of service model for the cycloruta, Bogota, Colombia
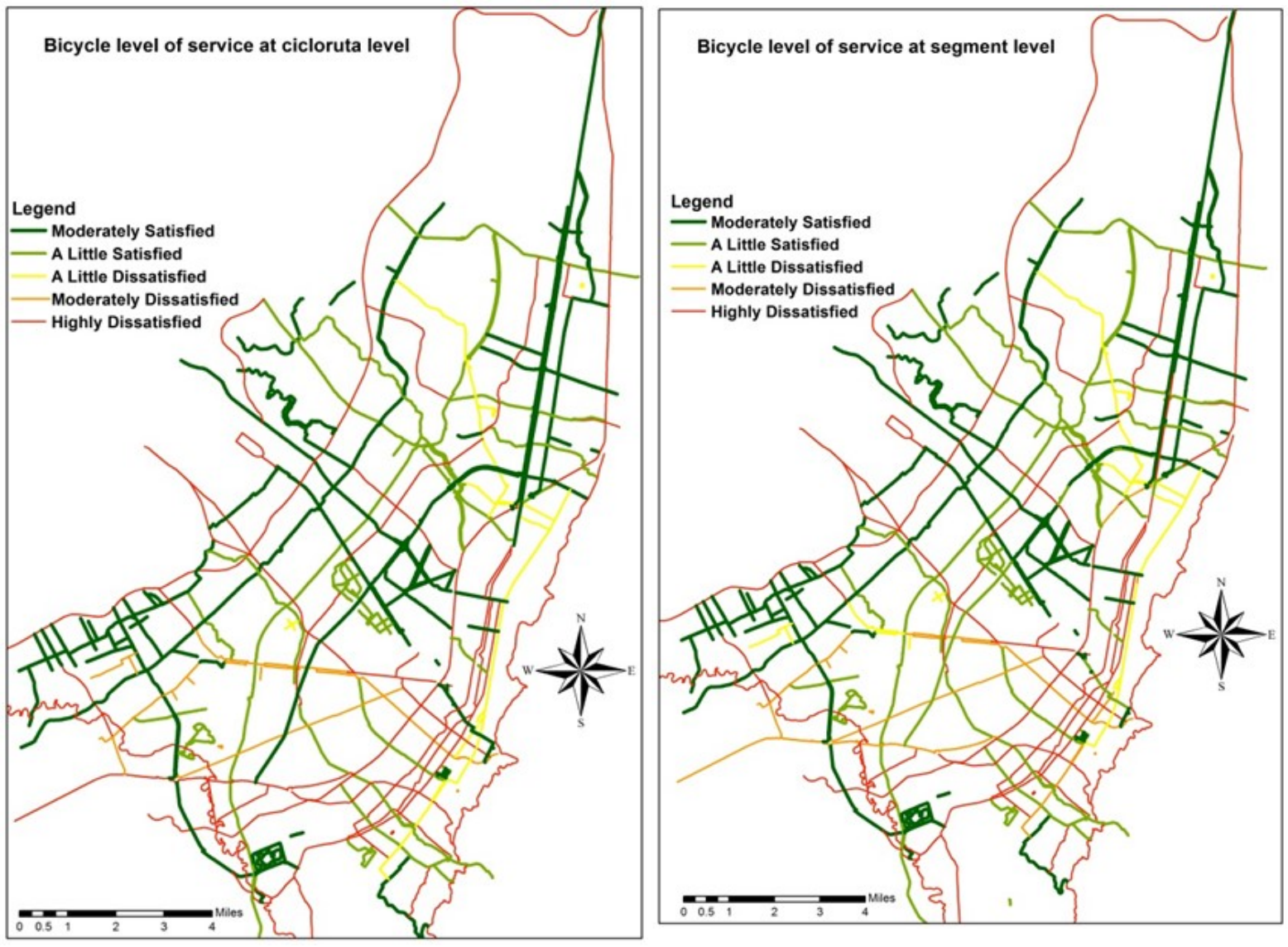

Figure 5. Estimated BLOS at both segment and Cicloruta levels
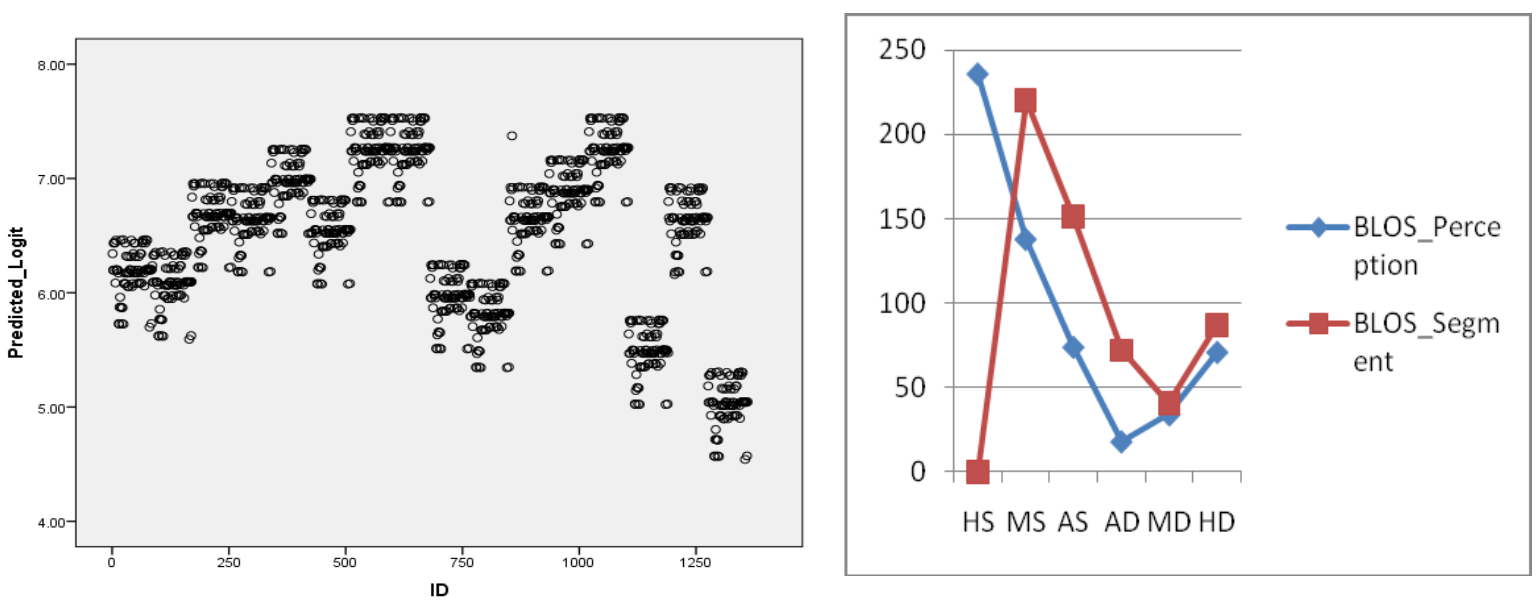

Figure 6. Predicted logit across all responses; and comparison between rated satisfaction and estimated scores 
ROMANIAN JOURNAL

OF TRANSPORT INFRASTRUCTURE

Inah Eteng OKON, Carlos A. MORENO

Bicycle level of service model for the cycloruta, Bogota, Colombia

\section{DISCUSSION OF FINDINGS}

Major findings of this research included the estimation of BLOS segment models using parameter estimates for satisfaction levels and coefficients for side path separation (0.605.SPS), vehicle speed (0.717.VS), motorised through volume (- 0.381.MTV) and conflicts with pedestrian and other cyclists (1.173.CWP).Most important is the determination of factors that affect bicyclists LOS and the ability to quantify these effects across different variables. Table 8 shows the marginal effects for participants perceived level of satisfaction in the model.

Bicycle lane width is obtained as 1 if it is greater than 2 meter wide, otherwise it is coded zero. This data was obtained from secondary sources and field work measurements carried out for validation. Estimation in Table 8 shows that a unit increase in bike lane would increase participants' perceived satisfaction such that the probability of becoming highly satisfied is 0.5192 , higher than all other satisfaction levels. On the other hand, the probability for a highly dissatisfied rating from participants due to a unit change in width is lowest at 0.0739 .

Curb lane (wide outside lane) was measured in terms of the class of arterial adjoining the segment. Generally, segments adjoining highway were scored zero since such roads are observed to be wider than 10 feet. Were the adjoining road is an arterial, the segment is awarded a score of 1 . Since less width is scored 1 , therefore, any unit reduction in the width of curb lane would have the least probability for highly dissatisfied satisfaction level, while as expected the probability of highly satisfied is 0.4906 as the highest.

Pavement condition of bicycle lanes was observed to be generally satisfactory as many segments of the Ciclorutas are second and third generation constructed in 2005 and 2010 respectively. This probably accounts for the nonstatistical relevance of this important variable in the model. Good conditions observed by the author were assigned a value of 1 and zero otherwise. However, the probability of a highly satisfied rating from a unit improvement in the quality of pavement is 0.5200 and decreases sharply to 0.0741 as highly dissatisfied. Subsequent models may have its contribution statistically validated depending on its overall quality across the network.

Side path separation is defined generally as physical separation of Cicloruta from motorised arterial either by trees, grasses or raised shoulder. Where any of these exist, a value of 1 is assigned, zero otherwise. A unit improvement of this variable indicates a high (0.6447) probability value for a highly satisfied rating. The same cannot be said of highly dissatisfied as the 
probability score is low, 0.0739 . Therefore, the more side path separation facilities are incorporated in the design of bicycle paths, the higher the probability for a high satisfaction rating from users. This is also consistent with the findings of (Jensen, 2007), that the more separated bike paths are away from curb lanes and pedestrian walkway, the more likelihood for high satisfaction levels. Garrard et al. (2008) also used multinomial logistic regression statistics to examine the impact of gender on the use of cycle paths with different separation paths, and found out the preference of female cyclists to off-road paths over nonbicycle paths with an odd ratio of 1.43 at 0.05 confidence interval. They also observed female preference for off-road paths to cycle lanes with an odd ratio of 1.34 .

Table 8. Matrix of average marginal effects for the perceived LOS (segment) model

\begin{tabular}{llllllll}
\hline $\mathrm{s} / \mathrm{n}$ & Variable & HS $\mathbf{y}=\mathbf{1}$ & $\mathbf{M S} \mathbf{y}=\mathbf{2}$ & $\mathbf{A S} \mathbf{y}=\mathbf{3}$ & $\mathbf{A D} \mathbf{y}=\mathbf{4}$ & MD $\mathbf{y}=\mathbf{5}$ & $\mathbf{H D} \mathbf{y}=\mathbf{6}$ \\
1 & BLW & 0.5192 & 0.4782 & 0.3222 & 0.1886 & 0.1343 & 0.0739 \\
2 & WOL & 0.4906 & 0.4522 & 0.3020 & 0.1725 & 0.1228 & 0.0664 \\
3 & PCL & 0.5200 & 0.4789 & 0.3228 & 0.1891 & 0.1347 & 0.0741 \\
4 & SPS & 0.6447 & 0.4782 & 0.3872 & 0.1886 & 0.1680 & 0.0739 \\
5 & NTL & 0.6197 & 0.5511 & 0.3728 & 0.2269 & 0.1604 & 0.0903 \\
6 & VS & 0.6395 & 0.5650 & 0.3822 & 0.2339 & 0.1652 & 0.0933 \\
7 & MTV & 0.4873 & 0.4501 & 0.3007 & 0.1716 & 0.1223 & 0.0661 \\
8 & CWP & 0.7335 & 0.6234 & 0.4201 & 0.2616 & 0.1836 & 0.1046 \\
9 & TB & 0.5395 & 0.4947 & 0.3342 & 0.1979 & 0.1408 & 0.0780 \\
10 & DAYLIGHT & 0.6522 & 0.5765 & 0.3909 & 0.2409 & 0.1699 & 0.0963 \\
11 & RAIN & 0.5442 & 0.4983 & 0.3369 & 0.2000 & 0.1422 & 0.0789 \\
12 & EXPERIENCE & 0.5470 & 0.5157 & 0.3493 & 0.2094 & 0.1487 & 0.0831 \\
13 & RIDE & 0.5668 & 0.5005 & 0.3385 & 0.2012 & 0.1431 & 0.0795 \\
14 & GENDER & 0.5051 & 0.4660 & 0.3130 & 0.1814 & 0.1292 & 0.0706 \\
15 & AGE & 0.6447 & 0.5711 & 0.3872 & 0.2379 & 0.1680 & 0.9662 \\
\hline
\end{tabular}

The number of through lanes refers to the number of through lanes adjoining bicycle paths. One of the challenges of bicycle use in Bogota is the location of cycle paths in mainly arterials and highways. Interviewed users decry the non-continuity of paths especially in residential neighbourhoods as this, according to them, discourages home-based associated trips with the bicycle (figure 7). Many segments end abruptly with or without posted signs. Many ciclocarrils are also rated low as the level of safety regarding collision with motor cars is high (figure 7). Measurement of this variable was by use of relevant street maps and field work validation to assign a value of 1 to cycle paths with equal to or less than 2 adjoining motorised lanes, zero otherwise. 
ROMANIAN JOURNAL

Therefore, the location of cycle paths in motorised arterials of less than 2 through lanes predicts higher level by 0.6197 or 62 per cent and highest dissatisfaction with a low probability of 0.0903 or 1 per cent probability.

Vehicle speed highly correlates with number of through lanes. In most observed cases in the study area, the number of through lanes increases the speed and volume of traffic along that arterial or highway. However, there were not observed posted speed limits in the city. In view of the Highway Capacity Manual (2012) definition of vehicle speed as good in urban areas if equal to or less than 35 miles per hour and observed traffic conditions in the study area, we therefore defined good vehicle speed as 1 if less or equal $30 \mathrm{mi} / \mathrm{hr}$ and bad if greater, therefore zero value assigned. As expected, the highest probability score of 0.6395 predicts highest satisfaction for users and decreases progressively to 0.0933 for highly dissatisfied. The high correlation between these two variables may offer a valid explanation for the exclusion of one (NTL) in the model. This corroborates some of the findings in Jensen (2007), about the significant impact of speed on satisfaction level of bicyclists. In his model, speed had a coefficient of 0.000421 . Other variables also considered in his model of similar contribution in our model include the "width of buffer area between facility and drive lane on the nearest roadside ( $\mathrm{LBUF}=-2.3895$ ).

Motorised traffic volume was based on secondary data obtained from Movilidad (2013) traffic census. Based on estimated averages across the city network, a value of 1 is assigned to traffic volume of equal or less 600 cars/15mins, zero if greater. The probability that users would derive highest satisfaction level when motorised traffic volume is less than 600 cars $/ 15 \mathrm{mins}$ is 0.4873 . The impact of motorised traffic volume remains an important aspect, in regard to the level of

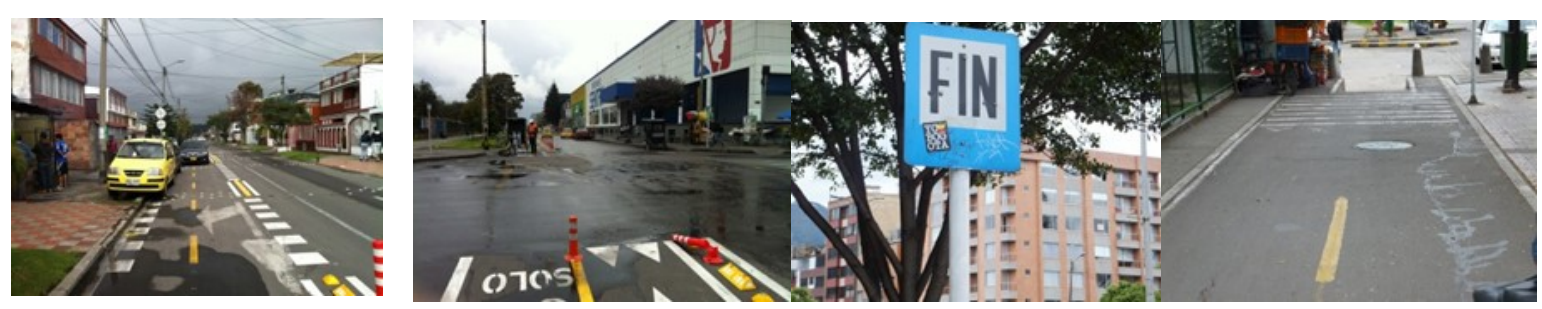

Figure 7. Typical ciclocarril been contested by cars other non-motorised mode; signage warning cyclists of segment termination 
ROMANIAN JOURNAL

OF TRANSPORT INFRASTRUCTURE

Inah Eteng OKON, Carlos A. MORENO

Bicycle level of service model for the cycloruta, Bogota, Colombia

satisfaction for cyclist in view of vehicle-bicycle related accidents. A unit reduction in the volume of traffic has a low prediction for highly dissatisfied. However, this findings corroborates research results earlier carried out on the attractiveness of bicycle paths in Germany (Bohle, 2000).

Trees and benches provide important elements in any cycling network as they provide shade, aesthetics and a feeling of safety to cyclists. They were observed across the network and where they exist or there is the presence of a raised shoulder we assign a value of 1 , otherwise zero is given.

Many ciclocarrils (figure 7) were assigned value of zero owing to little difference the separation makes in the feeling of safety among cyclists. A unit improvement in this variable strongly predicts highly satisfied (0.5395), whereas, highly dissatisfied is 0.0780 .

Daylight, rain, experience, and ride all exhibit a strong probability for highly satisfied level of service. Cycling during the day for instance is desirable by cyclists than night cycling. Sample was drawn from a segment video filmed at night during a ciclopeaso event. In addition, daylight was assigned 1 and zero for night. The probability that cyclists will be highly satisfied cycling during the day is 0.6522 compared to 0.0963 for highly dissatisfied. Rain also records a greater probability for highly satisfied $(0.5442)$ than for highly dissatisfied (0.0789). Higher riding experience also predicts the high perception of satisfaction $(0.5668)$ than in-experienced cycling with a 0.0831 probability for highly dissatisfied. This has a relationship with the confidence level of cyclist as a measure of their cycling experience. A measure of this experience was exhibited by members of Bogota Humana cycling agency that participated in some field surveys, as they could ride through perceived unsafe and un-built Ciclorutas at such great speed that kept the author gasping for breath. In terms of gender, since male was coded 1 and female 0 , the result therefore suggests that being a male increases the probabilities of higher satisfaction perception than being a female does. Table 8 reveals 0.5051 highly satisfied probability rating and 0.0706 highly dissatisfied levels. An interesting result was obtained for age. The data was coded 1 for ages equal to or less than 35 years, zero otherwise obtained from participants. The probabilities decrease from 0.6447 for HS to $0.5711,0.3872,0.2379$ and 0.1680 for MS, AS, AD, and MD respectively. The probabilities score for HD suddenly rose to 0.9662 . This can be explained by an apparently large young age group, 17-35, providing such a mix in perception of satisfaction that it is difficult to predict. In most cases, younger population are less sensitive to level of satisfaction. 


\section{CONCLUDING REMARKS AND POLICY RECOMMENDATIONS}

The aggregation of participant's ratings across of 16 videos representing 574 segments of 71 Ciclorutas may not reflect actual perception level across the study area. This is in view of the small sample size which the scope of this study accommodates. Further studies may validate perception of bicyclists using a larger sample size to examine levels of satisfaction. The sample size of participants, comprising over 70 per cent student participants and overall age of participants as over 80 per cent less than 35 years, has the tendency to influence our rating of satisfaction level as many studies have posited.

The study has provided an empirical methodology for estimating the level of satisfaction that bicyclists derive from the use of the Cicloruta, and by extension made a contribution to the existing body of literature on the subject matter. The methodology is suitable for application in many countries with modification on scoring of variables. The findings confirm the validity of the use of video data in combination with other geometry, physical and operational traffic characteristics as opposed to Epperson (1994) suggestion that video simulation alone can be used to simulate LOS model.

The estimated BLOS model can provide traffic and other infrastructure planners the ability to rate the level of satisfaction of cyclists in Bogota. This is a way to achieve better plans and designs of bicycle networks that optimizes national and local budgets. The model also provides an evaluation tool for existing Ciclorutas, so planners can undertake specific improvement measures for respective segments in the network. Already existing improvement plans on the Cicloruta can be compared with the result of this research to prioritise investment on high priority areas of the network. Specifically, along the Av. El Dorado, a deliberate plan to introduce some access and egress into the network is recommended.Facility inventory, efficiency and improvements can also be measured using this model. It can also be usedto determine minimum LOS standards along specific Ciclorutas as well as set targets, given road type,posted speed limits, land use type, pavement quality, path separation as well as cyclist characteristics. Forexample, higher BLOS standards such as ' $\mathrm{B}$ ' should be targeted at Ciclorutas around school areas, hospital, government ministries and so on. 
ROMANIAN JOURNAL

OF TRANSPORT INFRASTRUCTURE

Inah Eteng OKON, Carlos A. MORENO

Bicycle level of service model for the cycloruta, Bogota, Colombia

Proper enlightenment of cyclists on safety issues such as speed, phone use and other form of conversations that has the tendencies to detract cyclist while on the road is recommended. Motorists should be made aware of the right of the cyclist especially in shared lanes like the ciclocarrils while programmes that highlight the dangers of speed should also be emphasized. Bicycle use amongst children of school going age should be encouraged to inculcate in young people the culture of cycling. In this regard therefore, there should be an improved effort to develop suitable programmes in school curriculum that highlights some of these issues among road users irrespective of age, sex and income. Enlightenment programmes should also be directed at all urban residents on the need to respect traffic separation. This is in view of the frustration cyclist face with regular conflicts with pedestrian and other modes almost across the entire network. Dead-ends of some Ciclorutas suggest abandonment of projects, and should be completed.

\section{ACKNOWLEDGEMENTS}

The contribution of staff/management of Humana Bogota, Instituto de Desarrollo Urbano (IDU), IDECA, Piloto University, Los Andes University, Rosario University, Despacio and Movilidad is well acknowledged. This work is particularly dedicated to Cesar Criollo, who was brutally murderedon the 29th December 2014, while riding his bike in Flandes Municipality, Cundinamarca. Cesar was instrumental in planning and arranging the section rides in the fieldwork data collection and took part in many data collection activities. Without his inputs, this research would not have been possible. May his gentle soul rest in peace.

\section{REFERENCES}

[1] BANISTER D. Sustainable urban development and transport-a Eurovision for 2020. Transport Reviews, 20(1), 113-130, (2000).

[2] BBC News Magazine, 2013 (8 August)

[3] BHAT, C. An analysis of evening commute stop-making behavior using repeated choice observations from a multi-day survey. Transportation Research Part B: Methodological,33(7),495-510.doi:http://dx.doi.org/10.1016/S01912615(99)00003-X, (1999).

[4] BOHLE, W. Attractiveness of bicycle-facilities for the users and evaluation of measures for the cycle-traffic. Paper presented at the Traffic Safety on Two Continents Conference (pp. 89-94), (2000).

[5] CERVERO, R. Progressive Transport and the Poor: Bogota's Bold Steps Forward. (2005). 
ROMANIAN JOURNAL

OF TRANSPORT INFRASTRUCTURE

Inah Eteng OKON, Carlos A. MORENO

Bicycle level of service model for the cycloruta, Bogota, Colombia

[6] DAVIS, W. J. Bicycle safety evaluation. Auburn University. (1987).

[7] DIXON, L. B. Bicycle and pedestrian level-of-service performance measures and standards for congestion management systems. Transportation Research Record: Journal of the Transportation Research Board, 1538(1), 1-9. (1996).

[8] EDDY, N. Developing a level of service for bicycle use. Paper presented at the Pro Bike Pro Walk 96: Forecasting the future, Portland, Me. (1996).

[9] EPPERSON, B. Evaluating suitability of roadways for bicycle use: Toward a cycling level-of-service standard. In Transportation Research Record 1438, TRB, National Research Council Board, Washington, DC. (1994).

[10] FRIDSTRØM, L., IFVER, J., INGEBRIGTSEN, S., KULMALA, R., \& THOMSEN, L. K. Measuring the contribution of randomness, exposure, weather, and daylight to the variation in road accident counts. Accident Analysis \& Prevention, 27(1), 1-20. doi: http://dx.doi.org/10.1016/0001-4575(94)E0023-E. 1995.

[11] GARRARD, J., ROSE, G., \& LO, S. K. Promoting transportation cycling for women: The role of bicycle infrastructure. Preventive Medicine, 46(1), 55-59. doi: http://dx.doi.org/10.1016/j.ypmed.2007.07.010 (2008).

[12] GREENE, W. H., \&HENSHER, D. A. Modelling ordered choices: New York (2009).

[13] HANKEY, S., LINDSEY, G., WANG, X., BORAH, J., HOFF, K., UTECHT, B., \&XU, Z. Estimating use of non-motorized infrastructure: Models of bicycle and pedestrian traffic in Minneapolis, MN. Landscape and Urban Planning, 107(3), 307-316. doi: http://dx.doi.org/10.1016/j.landurbplan.2012.06.005. (2012).

[14] HARKEY, D. L., REINFURT, D. W., \&KNUIMAN, M. Development of the bicycle compatibility index. Transportation Research Record: Journal of the Transportation Research Board, 1636(1), 13-20. (1998).

[15] HICKMAN, R., SAXENA, S., BANISTER, D., \&ASHIRU, O. Examining transport futures with scenario analysis and MCA. Transportation Research Part A: Policy and Practice, 46(3), 560-575. doi:

[16] http://dx.doi.org/10.1016/j.tra.2011.11.006 (2012).

HULL, A. Transport matters: integrated approaches to planning city-regions:

[17] Routledge Ltd. (2010).

HCM Highway Capacity Manual, Transportation Research Board, National

[18] Research Council, Washington D.C. .(2000).

IDU. Ciclorutas. Instituto de Desarrollo Urbano (IDU), City of Bogota, Colombia.

[19] Available at: http://www.idu.gov.co/web/guest/espacio_Ciclorutas. (2009).

JENSEN, S. U. Pedestrian and Bicyclist Level of Service on Roadway Segments. Transportation Research Record: Journal of the Transportation Research Board,

[20] 2031(1), 43-51. (2007).

KANG, K., \& LEE, K. Development of a bicycle level of service model from the

[21] user's perspective. KSCE Journal of Civil Engineering, 16(6), 1032-1039. (2012).

KENWORTHY, J. R. Chapter 9 - Energy Use and CO2 Production in the Urban Passenger Transport Systems of 84 International Cities: Findings and Policy Implications. In D. Peter (Ed.), Urban Energy Transition (pp. 211-236).

[22] Amsterdam: Elsevier. (2008). 
ROMANIAN JOURNAL

OF TRANSPORT INFRASTRUCTURE

Inah Eteng OKON, Carlos A. MORENO

Bicycle level of service model for the cycloruta, Bogota, Colombia

[23] Transportation.Gwacheoun (2001).

LANDIS, B. W., VATTIKUTI, V. R., OTTENBERG, R. M., MCLEOD, D. S., \&GUTTENPLAN, M. Modeling the roadside walking environment: pedestrian level of service. Transportation Research Record: Journal of the Transportation

[24] Research Board, 1773(1), 82-88. (2001).

LANDIS, B. W., VATTIKUTI, V. R., \&BRANNICK, M. T. Real-time human perceptions: toward a bicycle level of service. Transportation Research Record:

[25] Journal of the Transportation Research Board, 1578(1), 119-126 (1997).

LANDIS, B. W. Bicycle interaction hazard score: a theoretical model. Transportation Research Record 1438, TRB, National Research Council,

[26] Washington, DC, 3-8. (1994).

LANDIS, B. W. Bicycle System Performance Measures: The Interaction Hazard

[27] and Latent Demand Score Models. ITE Journal, 66(2). (1996).

LANDIS, B. W., VATTIKUTI, V. R., OTTENBERG, R. M., PETRITSCH, T. A., GUTTENPLAN, M., \& CRIDER, L. B. Intersection level of service for the bicycle through movement. Transportation Research Record: Journal of the Transportation

[28] Research Board, 1828(1), 101-106. (2003).

MCPB. Fiscal year 94 Annual Growth Policy. Motgomery County Planning Board

[29] and Maryland National Capital Park and Planning Commission, Dec, 1992.

MOHAN, D., \&TIWARI, G. Sustainable transport systems: Linkages between environmental issues, public transport, non-motorised transport and safety.

[30] Economic and Political Weekly, 1589-1596. (1999).

NELDER, J. A., \&WEDDERBURN, R. W. M. (1972).Generalized Linear Models.Journal of the Royal Statistical Society. Series A (General), 135(3), 370-

[31] 384. doi: 10.2307/2344614

OKON, I., BRUSSEL, M. J. G., VAN DEN BOSCH, F. H. M., MORENO, C. A., and van Maarseveen, M. F. A. M. A statistical approach to the estimation of bicycle level of service models for the Cicloruta in Bogota, Colombia. Urban Transport

[32] XXIII, Vol 176, 265-282. doi:10.2495/UT170231 (2018)

PROVIDELO, J. K., \& DA PENHASANCHES, S. Roadway and traffic

[33] characteristics for bicycling. Transportation, 38(5), 765-777. (2011).

QI, Y., SMITH, B. L., \&GUO, J. Freeway accident likelihood prediction using a panel data analysis approach. Journal of transportation engineering, 133(3), 149-

[34] 156. (2007).

RCI. Florida Road Index, Development of the Bicycle Compatibility Index: A level

[35] of service concept. Retrieved from (1998).

SENER, ELURU, \&BHAT, An analysis of bicycle route choice preferences in

[36] Texas, US.Transportation, 36(5), 511-539, 2009

SISSON, S. B., LEE, S. M., BURNS, E. K., \& TUDOR-LOCKE, C. Suitability of Commuting by Bicycle to Arizona Elementary Schools. American Journal of Health

[37] Promotion, 20(3), 210-213. doi: 10.4278/0890-1171-20.3.210 (2006).

SORTON, A., \& WALSH, T. Bicycle stress level as a tool to evaluate urban and suburban bicycle compatibility. Transportation Research Record, TRB, National

[38] Research Council, Washington, D. C., 17-24. (1994). 


\section{ROMANIAN JOURNAL \\ OF TRANSPORT INFRASTRUCTURE}

Inah Eteng OKON, Carlos A. MORENO

Bicycle level of service model for the cycloruta, Bogota, Colombia

TITZE, S., STRONEGGER, W. J., JANSCHITZ, S., \&OJA, P. Association of built-environment, socialenvironment and personal factors with bicycling as a mode of transportation among Austrian city dwellers. Preventive Medicine, 47(3),

[39] 252-259. doi: http://dx.doi.org/10.1016/j.ypmed.2008.02.019 (2008).

WASHINGTON, S. P., KARLAFTIS, M. G., \& MANNERING, F. L. Statistical

[40] and econometric methods for transportation data analysis: CRC press. (2011).

WHYTE, W. H. City: Rediscovering the center: University of Pennsylvania Press.

[41] (1988).

[42] WHO.: Road traffic accidents death rate by country. World Health Organisation (2011).

WEY, W.-M., \& CHIU, Y.-H. Assessing the walkability of pedestrian environment

[43] under the transitoriented development. Habitat International, 38(0), 106-118. doi:http://dx.doi.org/10.1016/j.habitatint.2012.05.004 (2013).

YAZID, M. R. M., ISMAIL, R., \&ATIQ, R. The Use of Non-Motorized For Sustainable Transportation in Malaysia.Procedia Engineering, 20(0), 125-134. doi:http://dx.doi.org/10.1016/j.proeng.2011.11.147. (2011). 